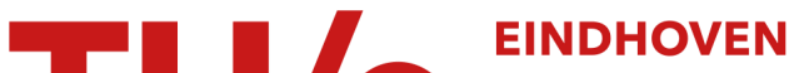 \\ UNIVERSITY OF \\ TECHNOLOGY
}

\section{Saturation of the hyperpolarizability of oligothiophenes}

\section{Citation for published version (APA):}

Thienpont, H., Rikken, G. L. J. A., Meijer, E. W., Hoeve, ten, W., \& Wynberg, H. (1990). Saturation of the hyperpolarizability of oligothiophenes. Physical Review Letters, 65(17), 2141-2144.

https://doi.org/10.1103/PhysRevLett.65.2141

DOI:

10.1103/PhysRevLett.65.2141

Document status and date:

Published: 01/01/1990

\section{Document Version:}

Publisher's PDF, also known as Version of Record (includes final page, issue and volume numbers)

\section{Please check the document version of this publication:}

- A submitted manuscript is the version of the article upon submission and before peer-review. There can be important differences between the submitted version and the official published version of record. People interested in the research are advised to contact the author for the final version of the publication, or visit the $\mathrm{DOI}$ to the publisher's website.

- The final author version and the galley proof are versions of the publication after peer review.

- The final published version features the final layout of the paper including the volume, issue and page numbers.

Link to publication

\section{General rights}

Copyright and moral rights for the publications made accessible in the public portal are retained by the authors and/or other copyright owners and it is a condition of accessing publications that users recognise and abide by the legal requirements associated with these rights.

- Users may download and print one copy of any publication from the public portal for the purpose of private study or research.

- You may not further distribute the material or use it for any profit-making activity or commercial gain

- You may freely distribute the URL identifying the publication in the public portal.

If the publication is distributed under the terms of Article 25fa of the Dutch Copyright Act, indicated by the "Taverne" license above, please follow below link for the End User Agreement:

www.tue.nl/taverne

Take down policy

If you believe that this document breaches copyright please contact us at:

openaccess@tue.nl

providing details and we will investigate your claim. 


\title{
Saturation of the Hyperpolarizability of Oligothiophenes
}

\author{
H. Thienpont, ${ }^{(a)}$ G. L. J. A. Rikken, and E. W. Meijer ${ }^{(b)}$ \\ Philips Research Laboratories, P.O. Box 80000, NL-5600 JA Eindhoven, The Netherlands \\ W. ten Hoeve and H. Wynberg \\ Syncom BV, University of Groningen, P.O. Box 2253, NL-9704 CG Groningen, The Netherlands
}

(Received 28 February 1990)

\begin{abstract}
We report the observation of saturation with chain length of the second hyperpolarizability of a series of long, well-defined, conjugated oligothiophenes. This saturation occurs at the same length as that of the band gap and of the polarizability, and is attributed to a saturation of the effective conjugation length. Solvatochromic and thermochromic measurements indicate that conformational effects play a role.

PACS numbers: $42.65 . \mathrm{Ky}, 33.90 .+\mathrm{h}$
\end{abstract}

Conjugated organic molecules have attracted much attention during the last decade for their nonlinear optical properties, both from a fundamental point of view and for their potential application in optical data processing. ${ }^{1}$ An important factor governing this nonlinearity is the effective conjugation length of the $\pi$-electron system. Many theoretical studies have been published that focus on the length dependence of both the polarizability $\alpha$ and the second hyperpolarizability $\gamma$ (Refs. $1-10$, and references therein). All of them predict a strong increase of $\gamma$ with chain length up to moderate lengths, assuming a planar molecular conformation. For long chain lengths in polyacetylene, at approximately fifteen double bonds, saturation of the second hyperpolarizability is predicted. ${ }^{6}$

Up to now, very little experimental data on the second hyperpolarizability of very long, well-defined, conjugated molecules have been published, ${ }^{10}$ merely due to the inaccessibility of these molecules. Recently, a systematic study was reported by Zhao, Singh, and Prasad ${ }^{11}$ for a series of oligothiophenes, ranging in length from one to six thiophene repeat units. They were able to describe their results for $\alpha$ and $\gamma$ with a power-law dependence on the number of repeat units $N$, implying no saturation of the conjugation up to $N=6$. On the other hand, the band gap $E_{g}$, determined from optical-absorption measurements, started to level off at $N=6$. They were prevented from going beyond $N=6$ by solubility problems.

Fichou et al. ${ }^{9}$ have reported measurements on thin solid films of some long oligothiophenes. However, the presence of many molecular conformations in such a material, as witnessed by a multitude of optical transitions in the absorption spectra, prevented the determination of the intrinsic molecular hyperpolarizability.

Since polythiophenes with 3-alkyl substituents are soluble in organic solvents, we have synthesized welldefined alkyl-substituted oligothiophenes. By using a new synthetic route, that will be published separately, we have made soluble oligomers with $N=3,4,5,7,9$, and
11 repeat units. The structures are given in Table I. In order to minimize steric hindrance and hence conformational disorder, we synthesized oligomers without adjacent alkyl groups. Here we report on measurements of the band gap, the polarizability $\alpha$, and the second hyperpolarizability $\gamma$ of these well-defined oligothiophenes.

Thin-film samples were prepared by introducing a few wt $\%$ oligothiophene in a polymethylmethacrylate (PMMA) matrix, using chlorobenzene as a solvent and spin coating on indium-tin-oxide-covered glass substrates. The maximum concentrations where no aggregation occurred, as monitored by the optical-absorption

TABLE I. Properties of the oligothiophenes I-VI, determined by optical-absorption measurements $\left(E_{g}\right)$, refractiveindex measurements at $632.8 \mathrm{~nm}(\alpha)$, and electric-fieldinduced second-harmonic generation (EFISH) at $1064 \mathrm{~nm}(\gamma)$, all in a PMMA matrix at room temperature.

\begin{tabular}{|c|c|c|c|c|}
\hline Molecule & $N$ & $E_{g}(\mathrm{eV})$ & $\alpha\left(10^{-23} \mathrm{esu}\right)$ & $\gamma\left(10^{-34}\right.$ esu $)$ \\
\hline I & 3 & 3.67 & 1.1 & 9.9 \\
\hline II & 4 & 3.13 & 1.4 & 22 \\
\hline III & 5 & 3.01 & 2.6 & 107 \\
\hline IV & 7 & 2.81 & 6.6 & 360 \\
\hline $\mathrm{V}$ & 9 & 2.78 & $\cdots$ & 370 \\
\hline VI & 11 & 2.77 & 7.0 & 460 \\
\hline & I & & II & \\
\hline & III & & $\mathrm{C}_{4} \mathrm{H}_{9} \quad \mathrm{C}_{4} \mathrm{H}_{9}$ & \\
\hline & $\nabla$ & & VI & \\
\hline
\end{tabular}




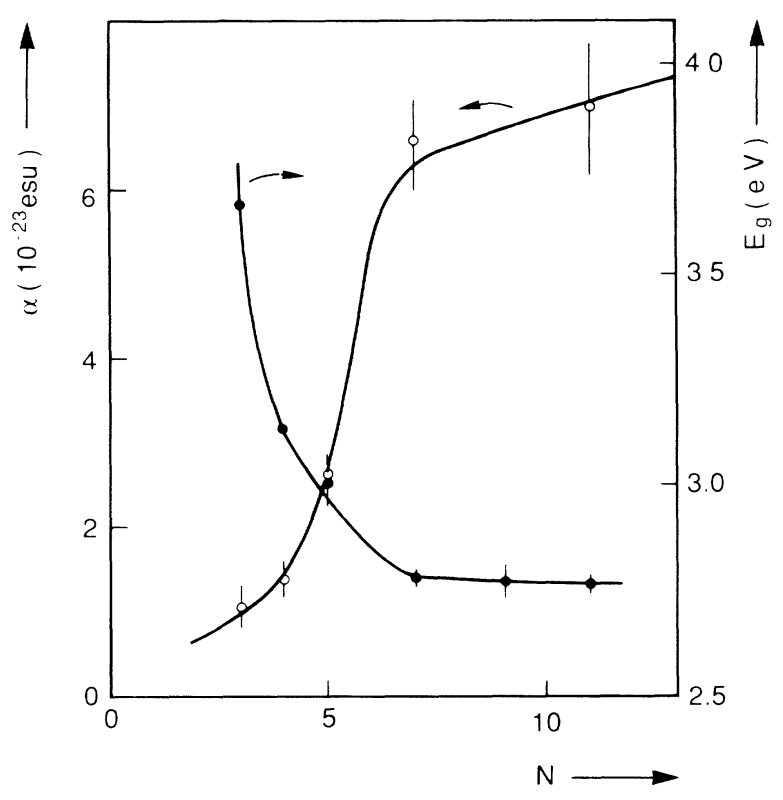

FIG. 1. Polarizability and band gap vs the number of repeat units for oligothiophenes in a PMMA matrix at room temperature. The solid lines are only meant to guide the eye.

spectra, ranged from $5 \mathrm{wt} \%$ for $N=3$ to $0.8 \mathrm{wt} \%$ for $N=11$. The polarizabilities were determined from accurate refractive-index measurements using $m$-line techniques at a wavelength of $632.8 \mathrm{~nm}$, assuming a constant PMMA density. This assumption may introduce a systematic error in the values for $\alpha$. Electric-field-induced second-harmonic generation (EFISH) was used to determine the orientation-averaged $\langle\gamma(-2 \omega ; \omega, \omega, 0)\rangle$ (Ref. 12) at room temperature at a fundamental wavelength of $1064 \mathrm{~nm}$. The dc electric field was applied by a corona discharge and determined by a compensation technique. $^{13}$ Fields up to $1.5 \mathrm{MV} / \mathrm{cm}$ were used in this way. The second-harmonic intensity was calibrated against that of a $y$-cut crystal quartz plate. From the symmetry of the molecules, only a very small permanent dipole moment and first hyperpolarizability will be present. Furthermore, the PMMA matrix at room temperature does not allow molecular reorientation on the time scale of the measurements (minutes). Therefore the contribution of the first hyperpolarizability of the oligothiophenes to the EFISH signal can be neglected. From the electric-field and concentration dependence, the contribution of the oligothiophenes to the third-order susceptibility can easily be determined.

The results are given in Table I and visualized in Figs. 1-3. A strong length dependence of $\alpha$ and $\gamma$ for $N \leq 7$ is observed, that changes into a much weaker, more or less linear one for $N>7$, where the band gap $E_{g}$ becomes constant. It should be noted that part of the increase in $\gamma$ with increasing chain length is due to an increasing resonance enhancement as the second-harmonic photon energy approaches the band gap. To a lesser extent, this

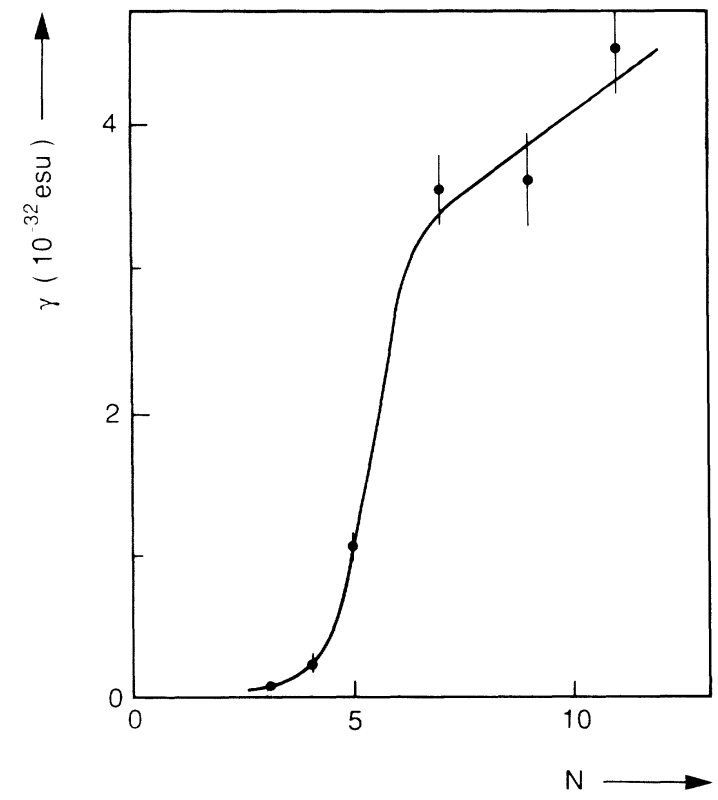

FIG. 2. Second hyperpolarizability vs the number of repeat units for oligothiophenes in a PMMA matrix at room temperature. The solid line is only meant to guide the eye.

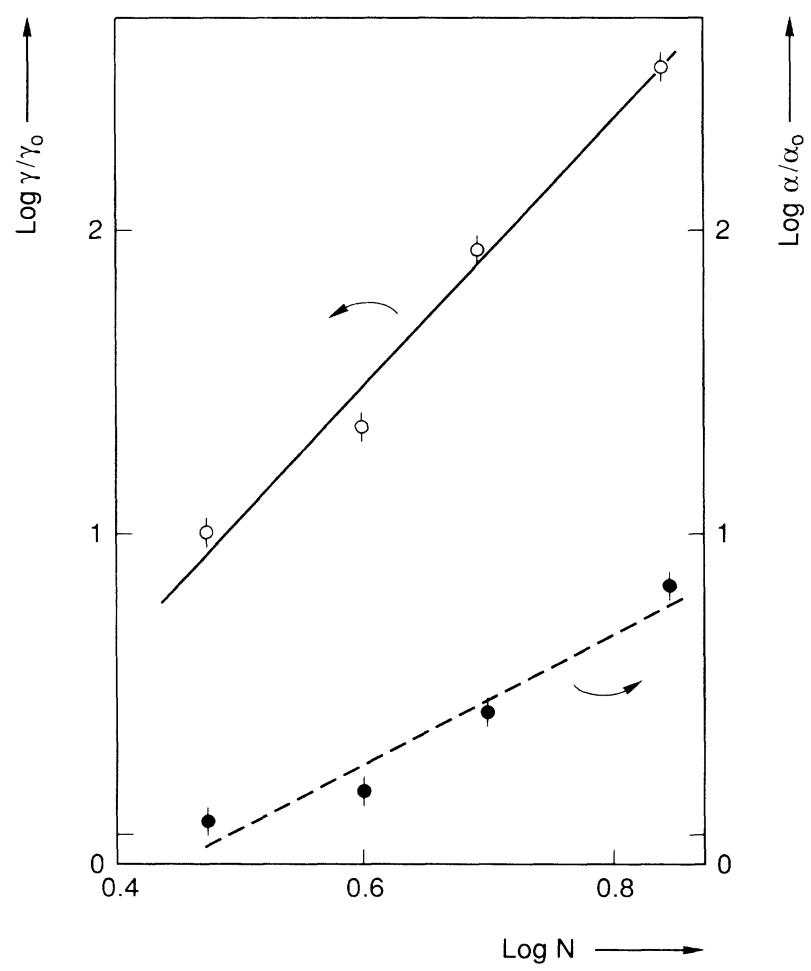

FIG. 3. Normalized polarizability and second hyperpolarizability vs the number of repeat units (up to $N=7$ ) for oligothiophenes in a PMMA matrix at room temperature. The lines represent power-law dependences with exponents of 2.4 (dashed) and 4.6 (solid). 
is also the case for the increase in $\alpha$. As a linear behavior is typical for nonconjugated molecules, ${ }^{10}$ these observations show that at the optical frequencies used here, for $N>7$ the oligothiophenes can no longer be considered as effectively conjugated over their entire length. Our values for $E_{g}$ agree with those reported by Zhao, Singh, and Prasad ${ }^{11}$ for $N \leq 5$, whereas our results for $\alpha$ are consistently lower than theirs. The cause for the discrepancy may lie in the systematic density error. Our results for $\gamma$ are consistently higher, which may be ascribed to the different measurement techniques and wavelengths used (degenerate four-wave mixing at 602 $\mathrm{nm}$ vs EFISH at $1064 \mathrm{~nm}$ ). If we describe the length dependence of $\alpha$ and $\gamma$ with a simple power law, we find the exponents to be 2.4 and 4.6, respectively (Fig. 3). Theoretical predictions range from 1.3 to 3 for the case of $\alpha$ and from 3.2 to 5.2 for the case of $\gamma$.

The saturation of $\gamma$ for $N>7$ can have an electronic or a conformational origin. The two can, however, not be regarded as independent: Electronic delocalization will increase the bond order of the bonds connecting the thiophene rings, which makes planar configurations energetically favorable. And vice versa, twisting around this bond will cause electronic localization on planar segments. This interrelation was clearly demonstrated by the calculations of Rossi and Viallat. ${ }^{14}$ It is very likely that the oligothiophenes as we studied them are not fully planar. Poly-3-alkyl-thiophenes show a strong solvatochromism and thermochromism, ${ }^{15,16}$ which are attributed to twisting of (groups of) rings around the connecting bond, ${ }^{17}$ disrupting the conjugation. We also observe solvatochromism and thermochromism for the longer oligothiophenes, albeit rather weak (for $N=11$ at room temperature, $E_{g}=2.92 \mathrm{eV}$ in 1-propanol and $E_{g}=2.71$ $\mathrm{eV}$ in tetrahydrofuran; for $N=5$ in 1-propanol, $E_{g}=3.01$ $\mathrm{eV}$ at $300 \mathrm{~K}$ and $E_{g}=2.94 \mathrm{eV}$ at $200 \mathrm{~K}$ ). This indicates that the molecules are not fully planar in a PMMA matrix at room temperature (for $N=5, E_{g}=3.01 \mathrm{eV}$; for $N=11, E_{g}=2.77 \mathrm{eV}$; see Table I) and that larger hyperpolarizabilities could be expected if the molecules could be planarized, especially for the longer ones. From small-angle neutron-scattering experiments, a statistical planar chain length of $5.5 \mathrm{~nm}$ was deduced for the poly3-alkyl-thiophenes, ${ }^{18}$ which corresponds to about fourteen repeat units. Although it is not clear how this length relates to the conjugation length relevant in optical measurements, these results are further support that conformational effects are important on a length scale comparable to the lengths of the molecules studied by us.

To our knowledge, no theoretical study of the length dependence of $\gamma$ for oligothiophenes has been published that takes both conformational and electron-correlation effects into account. Heflin et al. ${ }^{7}$ have shown that the latter is essential to obtain the correct sign and magnitude of the $\gamma$ of planar polyenes. Prasad, Perrin, and Samoc ${ }^{19}$ have presented a simple, empirical model that agrees very well with the results of Zhao, Singh, and
Prasad, " but the simplifications and the sensitivity to the parameter choice of this model do not allow for general conclusions to be drawn. The results of complete neglect of differential overlap calculations by Fichou et $a l .{ }^{9}$ of the length dependence of the band gap and the hyperpolarizability of fully planar oligothiophenes show a saturation of the gap at $N \geq 10$ and a transition to a weaker length dependence of $\gamma$ at the same length. For $N \leq 10$ they find a power-law dependence of $\gamma$ with an exponent of 4.3 , in fair agreement with our results. Furthermore, they confirm that the hyperpolarizability drops as the thiophene rings rotate around the connecting bond. As it is well established that the linear optical properties of the oligothiophenes are similar to those of the polyenes that would result from taking out the sulphur atom, ${ }^{20,21}$ a comparison with theoretical results for the second hyperpolarizability of polyenes seems meaningful. Heflin et al., ${ }^{7}$ assuming a planar conformation, have shown that the calculated $\gamma$ is determined by the geometrical length of the molecule. They find a power-law dependence of $\gamma$ on the length, with an exponent of 4.6, in excellent agreement with our experimental findings. They infer a saturation of $\gamma$ around 5$\mathrm{nm}$ chain length, which would correspond to roughly twelve thiophene rings. This value should be regarded as an upper limit for what could be expected experimentally, as the interrelation between electronic delocalization and conformation implies that the intrinsic, electronic saturation of conjugation will be accompanied by or preceded by a loss of planarity, depending on the forces on the molecule. The theoretical results of Beratan, Onuchic, and Perry ${ }^{6}$ for polyenes, using in essence an empirically parametrized single-particle model, imply saturation of the $\gamma$ of planar oligothiophenes between seven and eight repeat units. The good agreement with our results may be somewhat fortuitous, in view of the simplifications in the model.

It will be clear that further work is needed to fully understand the nonlinear optical properties of long conjugated molecules. As no molecule in a condensed phase can be considered to be fully planar, extension of current theories towards conformational effects and their interrelation with conjugation seems highly desirable. At the same time, experimental studies of the dependence of the nonlinearity on temperature and molecular environment are required. The aliphatic tails may provide a convenient extra handle in influencing the conformational effect.

In conclusion, we report the observation of saturation with chain length of the band gap, the first polarizability, and the second hyperpolarizability for oligothiophenes at about seven repeat units. To our knowledge, this is the first time that a saturation of the hyperpolarizability with chain length has been experimentally observed. The observation of solvatochromism and thermochromism indicates conformational effects to play a role in limiting the conjugation length. Obviously, understanding 
the causes for this saturation may have strong impact on the design and synthesis of thiophene-based nonlinear optical materials.

We gratefully acknowledge stimulating and helpful discussions with A. Seppen and E. E. Havinga.

(a) Visiting scientist from Vrije Universiteit Brussel, Dienst Toegepaste Natuurkunde, Pleinlaan 2, B-1050 Brussel, Belgium.

(b) Present address: DSM Research, P.O. Box 18, NL-6160 MD Geleen, The Netherlands.

'Nonlinear Optical Properties of Organic Molecules and Crystals, edited by D. S. Chemla and J. Zyss (Academic, New York, 1986), Vols. 1 and 2.

${ }^{2}$ E. F. McIntyre and H. F. Hameka, J. Chem. Phys. 68, 3481 (1978).

${ }^{3}$ S. C. Mehendale and K. C. Rustagi, Opt. Commun. 28, 259 (1979).

${ }^{4}$ M. G. Papadopoulos, J. Waite, and C. A. Nicolaides, J. Chem. Phys. 77, 2257 (1982)

${ }^{5}$ C. P. de Melo and R. S. Silbey, Chem. Phys. Lett. 140, 537 (1987).

${ }^{6}$ D. N. Beratan, J. N. Onuchic, and J. W. Perry, J. Phys. Chem. 91, 2697 (1987).

${ }^{7}$ J. R. Heflin, K. Y. Wong, O. Zamani-Khamiri, and A. F.
Garito, Phys. Rev. B 38, 1573 (1988).

${ }^{8}$ B. M. Pierce, J. Chem. Phys. 91, 791 (1989).

${ }^{9}$ D. Fichou, F. Garnier, F. Charra, F. Kajzar, and J. Messier, Spec. Publ.-R. Soc. Chem. 69, 176 (1989).

10 J. P. Hermann and J. Ducuing, J. Appl. Phys. 45, 5100 (1974).

${ }^{11}$ M. Zhao, B. P. Singh, and P. N. Prasad, J. Chem. Phys. 89, 5535 (1988)

${ }^{12}$ Nonlinear Optical Properties of Organic Molecules and Crystals (Ref. 1), Chap. III-2, and references therein.

${ }^{13}$ R. B. Comizolli, J. Electrochem. Soc. 134, 425 (1987).

${ }^{14}$ G. Rossi and A. Viallat, Phys. Rev. B 40, 10036 (1989); A. Viallat and G. Rossi, J. Chem. Phys. 92, 4548 (1990).

${ }^{15}$ S. D. D. V. Rughooputh, S. Hotta, and A. J. Heeger, J. Polym. Sci. Part B: Polym. Phys. 25, 1071 (1987).

${ }^{16}$ O. Inganas, W. R. Salaneck, J.-E. Osterholm, and J. Laasko, J. Synth. Met. 22, 395 (1988).

${ }^{17}$ W. R. Salaneck, O. Inganas, B. Themans, J. O. Nilsson, B. Sjogren, J.-E. Osterholm, J.-L. Bredas, and S. Svensson, J. Chem. Phys. 89, 4613 (1988).

18 J. P. Aime, F. Bargain, M. Schott, H. Eckhardt, G. G. Miller, and R. L. Elsenbaumer, Phys. Rev. Lett. 62, 55 (1989).

${ }^{19}$ P. N. Prasad, E. Perrin, and M. Samoc, J. Chem. Phys. 91, 2360 (1989).

${ }^{20}$ R. Eckert and H. Kuhn, Z. Elektrochem. 64, 356 (1960).

${ }^{21}$ A. O. Patil, A. J. Heeger, and F. Wudl, Chem. Rev. 88, 183 (1988). 